\title{
Bleaching Process Investigation of Tunisian Dromedary Hair
}

\author{
T. Harizi, S. Dhouib, S. Msahli, and F. Sakli \\ Textile Engineering Laboratory, Monastir University, B. P. 68, 5070 Ksar Hellal, Tunisia \\ Correspondence should be addressed to T. Harizi; tharizi@yahoo.fr
}

Received 10 April 2013; Accepted 12 May 2013

Academic Editors: J. Broda and B. Xu

Copyright (C) 2013 T. Harizi et al. This is an open access article distributed under the Creative Commons Attribution License, which permits unrestricted use, distribution, and reproduction in any medium, provided the original work is properly cited.

\begin{abstract}
Successful bleaching of pigmented fibres was, generally, evaluated by a maximum whiteness, a minimum yellowness, and less damage to the bleached fibers. A review of the literature reveals that many studies on pigmented fibre bleaching are concerned with improving the whiteness and mechanical properties of bleached fibres. In this study, we investigate the effects of the hydrogen peroxide concentration, bleaching time, and clarification bath on the bleaching efficiency of Tunisian dromedary hair. It was showed that 30 min bleaching time gives better result in term of whiteness. However, an increased bleaching time gives an excessive damage to the bleached fibers. Further, the damage incurred by the dromedary hair was more important than that for wool, as is shown by the tenacity results. We found that oxalic acid, which is used for rinsing dromedary hair (after bleaching), provides improved results in term of whiteness obtained with bleaching. Certainly, oxalic acid made it possible to remove the maximum of iron remaining on fibre after bleaching. Bleaching methods demonstrate the excessive damage incurred by the fibre when using hydrogen peroxide particularly with raise concentration. This damage leads to adverse effects on the tenacity fibre.
\end{abstract}

\section{Introduction}

The unique aesthetic quality of pure wool has made it irreplaceable even in a market dominated by its inexpensive and abundantly available synthetic versions such as acrylics. Wool constitutes a minor segment $(1.4 \%)$ of the total textile fibres produced globally [1]. However, a significant portion of the wool is consumed by the high-end fashion market because of its warmth, resiliency, and handle. Within animal hair fibres, specialty hair fibres are considered to be even more exquisite than sheep wool [2].

In particular, hair fibres are obtained from animals other than sheep, such as, mohair, alpaca, lama, and camel [3]. These fibres, mostly obtained from animals native to remote corners of the world, have a very small annual production, but capture the best markets in the high fashion industry $[4,5]$. Therefore, in spite of a small quantitative contribution, the significance of wool and especially hair fibres in the apparel and textile industry cannot be underrated.

In nature, animal fibres such as dromedary hair are usually found in various shades of brown or grey, due to the natural pigment, melanin. For light pastel shade textile articles, it is essential to use white material, and this can be obtained by the depigmentation of coloured fibres. Currently, the method of depigmentation commonly used in industrial practice consists of a mordanting bath containing $\mathrm{Fe}^{++}$ions which precedes a bleaching process using hydrogen peroxide [6].

In literatures, different bleaching agents are studied [79]. However, hydrogen peroxide $\left(\mathrm{H}_{2} \mathrm{O}_{2}\right)$ is a widely used agent for the oxidative bleaching of wool and other pigmented animal fibres [10-16]. Its oxidation mechanism is reviewed in detail in the previous literatures $[6,8]$. During the oxidizing reaction, $\mathrm{H}_{2} \mathrm{O}_{2}$ is converted into the perhydroxyl species $\left(\mathrm{HO}_{2}{ }^{-}\right)$, which is responsible for bleaching. Since the $\mathrm{HO}_{2}{ }^{-}$ ion is relatively unstable and easily forms molecular oxygen $\left(\mathrm{O}_{2}\right)$, which escapes from the bleach solution reducing the bleaching effect [17], a stabilizer is often added to the bleaching bath. Additionally, the rate of decomposition of $\mathrm{H}_{2} \mathrm{O}_{2}$ rises with increases in temperature and $\mathrm{pH}$, as does the rate of bleaching [12].

Hydrogen peroxide $\left(\mathrm{H}_{2} \mathrm{O}_{2}\right)$ is an odorless liquid that is easily manageable and available in convenient and safe forms $[9,10,16]$. However, it causes damage to the fibre $[10,18]$. The damage arises from attack on amino acids in the keratin fibre, $[12,19]$. This damage can lead to adverse effects on the fibre's mechanical properties [16]. 
Bleaching is chemically damaging to the fibres. Choosing optimum processing conditions is essential to minimize damage [13, 20-23]. The chemical compounds generated from these reactions could affect the fibre properties and mechanical properties in particular.

This study evaluates the bleaching methods developed for pigmented dromedary hair. Different bleaching methods were used to bleach colored dromedary fibres. Investigation is concerning the effects of the hydrogen peroxide concentration, bleaching time, and clarification bath on whiteness and yellowness degree and mechanical properties. The bleaching effectiveness of the bleached fibre was presented.

\section{Experimental Procedures}

\subsection{Test Materials}

(i) Samples of Tunisian dromedary hair fleece of natural brown colored fibres (whiteness degree is 36.15 and yellowness index is 51.05) were scoured and dehaired before use for the bleaching process experience.

(ii) Samples of Tunisian scoured wool (whiteness degree is 56.18 and yellowness index is 34.06) are bleached for comparison of the dromedary hair bleaching results.

2.2. Depigmentation Process. The depigmentation process consisted of mordanting step followed by a bleaching step and was carried out at the experimental conditions (shown in Table 1).

The sample was depigmented (mordanting, rinsing, bleaching, and rinsing) at a fibre liquor ratio of 1:20 using a polycolor beaker dyeing apparatus. Different concentrations of hydrogen peroxide in the bleaching bath were tested. Concentrations of 3-4.5-6-7.5-9 g/L of hydrogen peroxide were used. After the bleaching step, each sample was divided in two parties; the first is rinsed only with pure water, and the second is rinsed with an oxalic acid. The fibres were then dried in air.

2.3. Evaluation on Bleaching Effect. The degree of whiteness and the yellowness index were measured on a Minolta CM-100 spectrophotometer using a D65 illuminant and a $10^{\circ}$ observer (ASTM E-313, ASTM D-1925). The degree of whiteness $\left(L=10 Y^{1 / 2}\right)$ and yellowness index $(\mathrm{YI}=100(X-$ $Z) / Y$ ) was calculated using the parameters $X, Y$, and $Z$ that are the measured red, green, and blue, respectively.

The extent of fibres degradation caused by bleaching was determined by measuring the tenacity of the samples. The mechanical parameters (tenacity and strain) were measured using a pendular dynamometer, "Stelometer," in accordance with the standard NF G 07307.

The precision of the data was evaluated by standard deviation. All the results are the mean value of three parallel experiments. For each sample, the degree of whiteness and the yellowness index were measured eight times at various positions on the sample. For mechanical properties, ten measures were realized for each sample.

\section{Results and Discussion}

3.1. Dromedary Hair Bleaching Results Compared to That of Wool. An individual bleaching wool test was included in this study only for comparison of the dromedary hair bleaching results. The whiteness index, yellowness index, and tenacity results are summarised in Table 2.

Table 2 shows the effectiveness of the dromedary hair bleached process as compared to that of wool for different bleaching times with $\mathrm{H}_{2} \mathrm{O}_{2}$ concentration equals $6 \mathrm{~g} / \mathrm{L}$.

Results of colour measurement show that degree of whiteness of bleached fibres is increased to 78.5 from 51 and to 77.7 from 56.1 for dromedary hair and wool, respectively. The yellowness index of bleached fibres is reduced to 23.7 from 36.1 and to 29.7 from 34. According to the indicated values, a considerable increase in whiteness degree and accordingly a decrease in yellowness index have occurred by the bleaching process. These whiteness and yellowness results of bleaching wool and dromedary indicate that both bleached fibres provide a good base for the dyeing of medium to deep shades.

Nevertheless, as seen from Table 2, results show that the effectiveness of bleaching process is higher for dromedary hair than wool in term of degree of whiteness and yellowness indices. This difference was attended when considering the findings $[6,24,25]$ in this subject. To limit the number of variable parameters, we used the same bleaching process for wool and dromedary hair which both have, initially, the same colour measurement approximately.

It is apparent that the damage incurred by the dromedary hair was more important than that for wool, as is shown by the tenacity results (Table 2 ). The tenacity value of bleached dromedary hair was considerably reduced (21\%) than that for wool (10.5\%). However, the untreated dromedary hair tenacity was very strong compared to untreated wool. In previous work, we presented in detail the mechanical properties of dromedary hair $[26,27]$. It is clear that the resistance loss incurred by the dromedary hair was greater than that for wool, but the bleaching dromedary hair tenacity remained even so superior to bleached wool tenacity.

3.2. Effect of Bleaching Time on Whiteness, Yellowness, and Degradability. To investigate the effect of different bleaching time on the bleaching efficiency of dromedary hair, a series of trials were performed using five different bleaching times. The whiteness and yellowness results are shown in Figure 1. Curves show an increase and decrease evolution of degree of whiteness yellowness index, respectively, according to the bleaching time. It can be seen from the figure that higher whiteness and lower yellowness values were obtained at bleaching time equal to $30 \mathrm{~min}$. After 30 minutes, the degree of whiteness decreases slightly and the yellowness index increases faintly. This may be due to the longer treatment in hot liquor [28]. These results show that optimum bleaching time is $30 \mathrm{~min}$ in tested conditions.

However, an increased bleaching time gives an excessive damage to the bleached fibers $[9,16,25]$. Indeed, the bleached fibres tenacity is significantly reduced in all cases, particularly at the long bleaching time. This is probably explained in term 
TABLE 1: Experimental conditions of depigmentation process for different fibres samples.

\begin{tabular}{llll}
\hline Mordanting & Rinsing & Bleaching & Rinsing \\
\hline $\mathrm{FeSO}_{4}: 2 \mathrm{~g} / \mathrm{L}$ & & $\mathrm{Na}_{4} \mathrm{P}_{2} \mathrm{O}_{7} \cdot 5 \mathrm{H}_{2} \mathrm{O}: 4 \mathrm{~g} / \mathrm{L}$ & Pure water \\
$\mathrm{Na}_{2} \mathrm{~S}_{2} \mathrm{O}_{4}: 1 \mathrm{~g} / \mathrm{L}$ & Cold water & $\mathrm{EDTA}_{2} \mathrm{~g} / \mathrm{L}$ & Or \\
$\mathrm{HCHO}(35-40 \%): 3 \mathrm{~g} / \mathrm{L}$ & Neutralisation with $\mathrm{NH}_{4} \mathrm{OH}$ & $\mathrm{H}_{2} \mathrm{O}_{2} 35 \%: 3-9 \mathrm{~g} / \mathrm{L}$ & $\mathrm{Oxalic}$ acid: $7 \mathrm{~g} / \mathrm{L}$ \\
$\mathrm{L} . \mathrm{R} .: 1: 20$ & $\mathrm{pH}: 11$ & $\mathrm{~L} . \mathrm{R} .: 1: 20$ & $\mathrm{Na}_{2} \mathrm{CO}: 8.5 \mathrm{~g} / \mathrm{L}$ \\
$\mathrm{pH}(\mathrm{HCO} 2 \mathrm{H}): 4$ & Temperature: $45^{\circ} \mathrm{C}$ & $\mathrm{pH}: 9$ & $\mathrm{pH}: 11$ \\
Temperature: $75^{\circ} \mathrm{C}$ & Time: 5 min & Temperature: $75^{\circ} \mathrm{C}$ & Temperature: $50^{\circ} \mathrm{C}$ Time: \\
Time: 60 min & & Time: $20-30-45-60 \mathrm{~min}$ & 5 min \\
\hline
\end{tabular}

TABLE 2: Effectiveness of the dromedary hair bleaching process compared to that of wool for 30 min bleaching times with $\mathrm{H}_{2} \mathrm{O}_{2}$ concentration equals $6 \mathrm{~g} / \mathrm{L}$.

\begin{tabular}{lcccc}
\hline Fibre types & Process & $\begin{array}{c}\text { Degree of } \\
\text { whiteness }^{\mathrm{a}}\end{array}$ & $\begin{array}{c}\text { Yellowness } \\
\text { index }^{\mathrm{b}}\end{array}$ & $\begin{array}{c}\text { Tenacity } \\
\text { cN/tex }^{\mathrm{c}}\end{array}$ \\
\hline $\begin{array}{l}\text { Dromedary } \\
\text { hair }\end{array}$ & Untreated & $51.05 \pm 1.2$ & $36.15 \pm 0.9$ & $18.18 \pm 1.8$ \\
Dark brown & Bleached & $78.54 \pm 0.7$ & $23.75 \pm 0.6$ & $14.17 \pm 2.5$ \\
wool & Bleached & $77.73 \pm 0.4$ & $29.73 \pm 0.6$ & $9.95 \pm 1.6$ \\
\hline
\end{tabular}

${ }^{a}$ As per ASTM E-313; mean value of 3 samples \pm standard deviation, each sample having 8 measurements. ${ }^{\mathrm{b}}$ As per ASTM D-1925; mean value of 3 samples \pm standard deviation, each sample having 8 measurements. ${ }^{\mathrm{c}}$ As per NF G 07 307; mean value of 3 samples \pm standard deviation, each sample having 10 measurements.

TABLE 3: Effect of rinsing after bleaching on the degree of whiteness and yellowness index of bleaching dromedary hair for $30 \mathrm{~min}$ bleaching times with $\mathrm{H}_{2} \mathrm{O}_{2}$ concentration equals $6 \mathrm{~g} / \mathrm{L}$.

\begin{tabular}{lccc}
\hline $\begin{array}{l}\text { Rinsing after } \\
\text { bleaching }\end{array}$ & $\begin{array}{c}\text { Degree of } \\
\text { whiteness }^{\mathrm{a}}\end{array}$ & $\begin{array}{c}\text { Yellowness } \\
\text { index }^{\mathrm{b}}\end{array}$ & $\begin{array}{c}\text { Tenacity } \\
\text { cN/tex }^{\mathrm{c}}\end{array}$ \\
\hline Untreated & $51.05 \pm 1.2$ & $36.15 \pm 0.9$ & $18.18 \pm 1.8$ \\
Pure water & $69.19 \pm 0.7$ & $43.05 \pm 0.6$ & $13.47 \pm 2.5$ \\
Oxalic acid & $78.48 \pm 1.1$ & $23.76 \pm 1.0$ & $14.12 \pm 2.7$ \\
\hline
\end{tabular}

${ }^{a}$ As per ASTM E-313; mean value of 3 samples \pm standard deviation, each sample having 8 measurements. ${ }^{\mathrm{b}}$ As per ASTM D-1925; mean value of 3 samples \pm standard deviation, each sample having 8 measurements. ${ }^{\mathrm{c}}$ As per NF G 07 307; mean value of 3 samples \pm standard deviation, each sample having 10 measurements.

of damage arising from hydrogen peroxide attack on amino acids in the keratin fibre.

3.3. Effect of Rinsing on Whiteness and Yellowness. In this experiment, bleaching of dromedary hair at different rinsing methods was carried out. Two different rinsing conditions (rinsing is after bleaching) are tried; the first is a rinsing only with pure water, and the second is a rinsing using oxalic acid. In this experiment, a bleaching time of $30 \mathrm{~min}$ and a hydrogen peroxide concentration of $6 \mathrm{~g} / \mathrm{L}$ were used. Table 3 presents the results of the effect of rinsing after bleaching on the degree of whiteness and yellowness index of bleaching dromedary hair. Results of colour measurement show that the yellowness index is reduced to 23.7 and increased to 43 from 36.1 for rinsing with pure water and rinsing using oxalic acid respectively. Also, the degree of whiteness is raised to 69.2

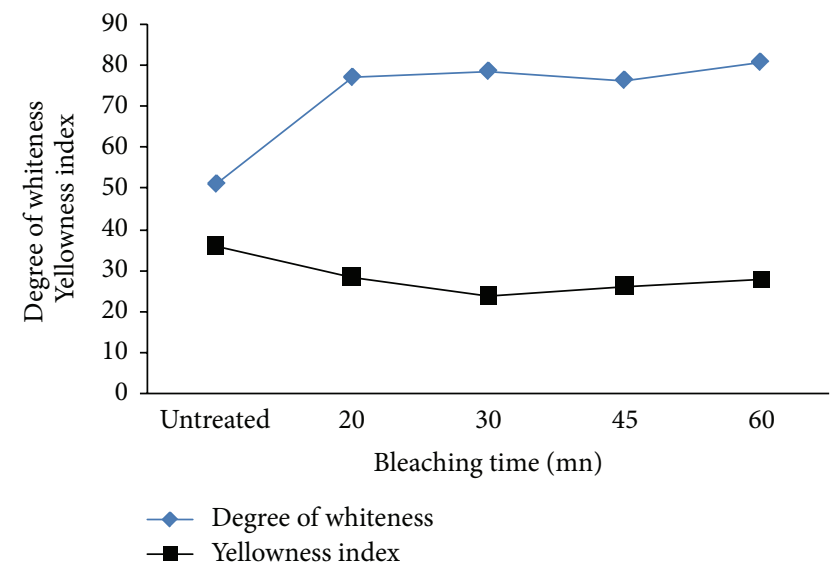

FIGURE 1: Effect of bleaching time on degree of whiteness and yellowness index.

and increased to 78.5 from 51.1 for rinsing with pure water and rinsing using oxalic acid, respectively. This indicates that rinsing (after bleaching) using oxalic acid provides a good base for the dyeing of medium to deep shades.

The oxalic acid would solubilise the iron present on dromedary hair after the bleaching stage and hence lighten the background discoloration. The reaction of oxalic acid with the residual hydrogen peroxide after the bleaching stage creates a highly reductive agent that reduces any ferric species that may be present on bleached dromedary hair to the ferrous form, which is easily washed away because of its much smaller affinity to white dromedary hair.

This problem of discoloration is due to the large amount of iron remaining on the fibres after mordanting process which cannot be significantly removed during rinsing. The aim of rinsing is to selectively remove iron associated with keratin [29]. Nevertheless, it is very difficult to completely remove all the residual iron once a large amount has been deposited [30].

Table 3 clearly demonstrates that oxalic acid, which is used for rinsing dromedary hair (after bleaching), provides improved results in term of whiteness obtained with bleaching. Certainly, oxalic acid made it possible to remove the maximum of iron remaining on fibre after bleaching.

3.4. Effect of Hydrogen Peroxide Concentration on Bleaching. To determine the effect of hydrogen peroxide concentration on bleaching of dromedary hair, a series of trials were 


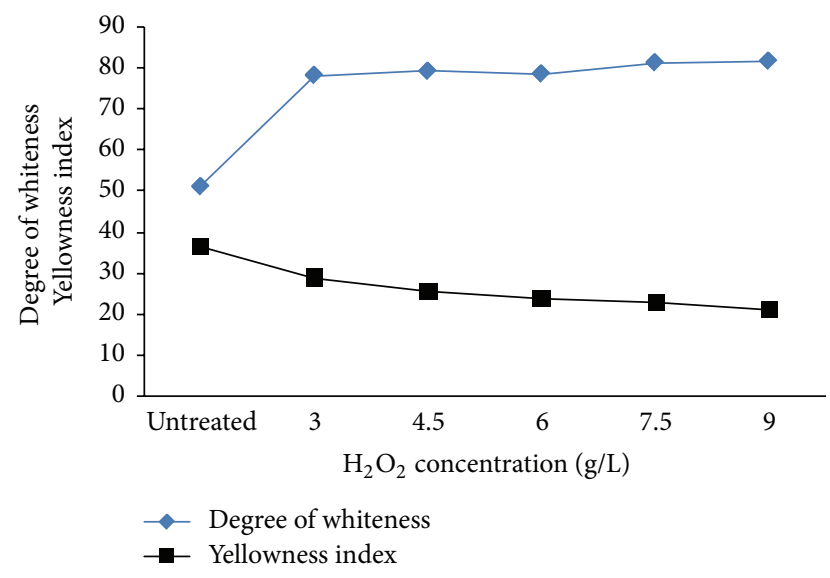

Figure 2: Yellowness index and degree of whiteness of bleached dromedary hair for different hydrogen peroxide concentration.

performed using five different hydrogen peroxide concentrations. The degree of whiteness and yellowness index results are shown in Figure 2. In this experiment we utilized samples with a bleaching time of $30 \mathrm{~min}$, and rinsing after bleaching was performed by using oxalic acid.

The results indicate an approximately linear relationship between the $\mathrm{H}_{2} \mathrm{O}_{2}$ concentrations and the yellowness index values. This also means that yellowness index decreases and degree of whiteness increases with increasing the $\mathrm{H}_{2} \mathrm{O}_{2}$ concentration. Maximum degree of whiteness index (81.7) and minimum yellowness index values (21.1) were obtained with $9 \mathrm{~g} / \mathrm{L} \mathrm{H}_{2} \mathrm{O}_{2}$, and there is no considerable difference between the whiteness and the yellowness indices with $9 \mathrm{~g} / \mathrm{L}$ and $7.5 \mathrm{~g} / \mathrm{L}$. The maximum whiteness degree which can be reached by $\mathrm{H}_{2} \mathrm{O}_{2}$ bleaching is not considered optimum unless provides a slightly low damage incurred by the dromedary hair.

Figure 3 present the tenacity evolution of bleached dromedary hair according to the hydrogen peroxide concentration. The curve shows a decrease evolution of the tenacity when the hydrogen peroxide concentration increases.

Figure 3 shows a sharp rapid decrease evolution in the tenacity between 0 and $3 \mathrm{~g} / \mathrm{L} \mathrm{H}_{2} \mathrm{O}_{2}$ concentrations, but from $3 \mathrm{~g} / \mathrm{L}$ to $6 \mathrm{~g} / \mathrm{L}$ the slope of the curve is decreased slowly. Raising the $\mathrm{H}_{2} \mathrm{O}_{2}$ concentration from 6 to $9 \mathrm{~g} / \mathrm{L}$ causes a dramatic decrease in tenacity value. This demonstrates the excessive damage incurred by the fibre when using hydrogen peroxide particularly with raised concentration. This damage leads to adverse effects on the tenacity fibre.

Generally, the changes in mechanical properties of hair keratin brought about by bleaching can be satisfactorily interpreted in terms of the oxidative attack on the disulfide bonds alone. The disulfide bonds contribute greatly to the wet strength of keratin fibers, which decrease almost linearly with the cystine content. It is, however, obvious that the main source of damage resides in the destruction of disulfide bonds $[24,31,32]$.

From Figures 2 and 3, the results clearly showed that a $\mathrm{H}_{2} \mathrm{O}_{2}$ concentration of $6 \mathrm{~g} / \mathrm{L}$ was optimal. Higher concentrations resulted in a deteriorated bleaching effect, and lower concentrations provided no significant improvements.

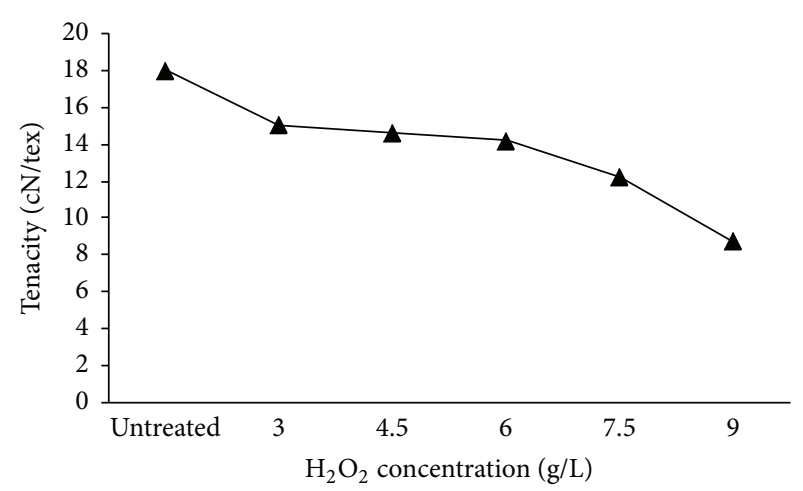

FIGURE 3: Tenacity evolution of bleached dromedary hair according to the hydrogen peroxide concentration.

\section{Conclusions}

We investigate the effects of the hydrogen peroxide concentration, bleaching time, and clarification bath on the bleaching efficiency of Tunisian dromedary hair. It showed that 30 min bleaching time gives better result in term of whiteness for different dromedary hair samples. However, an increased bleaching time gives an excessive damage to the bleached fibers. It is apparent that the damage incurred by the dromedary hair was more important than that for wool, as is shown by the tenacity results, but the bleaching dromedary hair tenacity remained even so superior to bleached wool tenacity.

A rinsing with oxalic acid, after bleaching, provides better whiteness and without more damage than rinsing only with pure water. Indeed, oxalic acid rinse effectively removes iron deposited on the fibres during mordanting, providing maximum whiteness.

We have established the conditions of bleaching process applicable to bleaching pigmented dromedary hair that provide maximum whiteness with minimum damage. Optimum results are obtained when bleaching time is $30 \mathrm{~min}$, hydrogen peroxide concentration is $6 \mathrm{~g} / \mathrm{L}$, and using oxalic acid for rinsing after bleaching.

Bleaching methods demonstrate the excessive damage incurred by the fibre when using hydrogen peroxide particularly with raised concentration. This damage leads to adverse effects on the tenacity fibre.

\section{References}

[1] The Fiber Year 2009/10 A World Survey on Textile and Nonwoven Industry-Oerlikon Textile, http://www.oerlikontextile .com/Portaldata/1/Resources/saurer_textile_solutions/media_ center/fiber_year_2009_10/The_Fibre_Year_2010_en_0607.pdf.

[2] Canadian Fashion and Design, "Specialty Fibers," 2002, http://www.ntgi.net/ICCF\&D/index2.html.

[3] K. L. Hatch, Textile Science, West Publishing Company, Minneapolis, Minn, USA, 1993.

[4] Veltjens 1996, 2005, http://www.surifarm.de/Lings.lings.htm.

[5] P. P. Rane and S. S. Barve, "Evaluating protein patterns of speciality fibres for identification to combat false labeling," 
International Journal of Zoological Research, vol. 6, no. 4, pp. 286-292, 2010.

[6] J. Knott, Fine Animal Fibres and Their Depigmentation Process, 1990.

[7] S. M. Smith, D. J. Westmoreland, and H. P. Schoots, "Colorclear technology, a new method of whitening of wool, machine washable wool and wool/cotton blends," in Proceedings of the 11th International Wool Research Conference, September 2005.

[8] “Technical Manual. Superwhite Australian Merino Using ColorClearTM WB Bleaching Technology," Australian Wool Innovation, 2013, http://www.csiro.au/files/files/pa70.pdf.

[9] D. Yilmazer and M. Kanik, "Bleaching of Wool with sodium borohydride," Journal of Engineered Fibers and Fabrics, vol. 4, no. 3, pp. 45-50, 2009.

[10] J. Cegarra and J. Gacen, "Bleaching of wool with hydrogen peroxide," Wool Science Review, vol. 59, no. 9, pp. 1-44, 1983.

[11] W. Chen, D. Chen, and X. Wang, "Surface modification and bleaching of pigmented wool," Textile Research Journal, vol. 71, no. 5, pp. 441-445, 2001.

[12] P. A. Duffield, Review of Bleaching, Textile Technology Group, IWS Development Centre, 1986.

[13] D. M. Lewis, Wool Dyeing, Society of Dyers and Colourists, 1992.

[14] J. A. Maclaren and B. Milligan, Wool Science: The Chemical Reactivity of the Wool Fibre, Science Press, 1981.

[15] J. T. Marsh, An Introduction to Textile Bleaching (Forth Impression), Chapman \& Hall, New York, NY, USA, 1956.

[16] X. Liu, C. Hurren, C. J, and X. Wang, "Comparative analyses of two selective bleaching methods an alpaca fibers," Fibers and Polymers, vol. 4, pp. 124-128, 2003.

[17] INTEROX, A Bleachers Handbook, Solvay \& Interox GMBH, 1983.

[18] J. Cegarra, J. Gacen, and M. Caro, "Optimization of the conventional bleaching of wool with hydrogen peroxide," Journal of the Society of Dyers and Colourists, vol. 94, no. 3, pp. 85-90, 1978.

[19] J. Gacen and D. Cayuela, "Comparison of wool bleaching with hydrogen peroxide in alkaline and acidic media," Journal of the Society of Dyers and Colourists, vol. 116, no. 1, pp. 13-15, 2000.

[20] P. R. Brady, Proceedings of the 7th International Wool Textile Research Conference, Tokyo, Japan, 1985.

[21] D. P. Collins, American Dyestuff Reporter, vol. 53, no. 16, pp. 218221, 1964.

[22] R. Convert, L. Schacher, and P. Viallier, Textile Science: Textile Chemistry and Finishing Section, 1998.

[23] J. Gacen, J. Cegarra, M. Caro, and L. Aizpurua, "A comparative study of bleaching untreated, chlorinated and hercosett-treated wool with hydrogen peroxide," Journal of Society of Dyers and Colourists, vol. 95, no. 11, pp. 389-395, 1979.

[24] A. Bereck, "Bleaching of pigmented speciality animal fibres and wool," Review of Progress in Coloration, no. 24, pp. 17-25, 1994.

[25] A. Khishigsuren, M. Nakajima, and M. Takahashi, "Effects of ferrous mordanting on bleaching of camel hair," Textile Research Journal, vol. 71, no. 6, pp. 487-494, 2001.

[26] T. Harizi, S. Msahli, F. Sakli, and T. Khorchani, "Evaluation of physical and mechanical properties of Tunisian camel hair," Journal of the Textile Institute, vol. 98, no. 1, pp. 15-21, 2007.

[27] T. Harizi, Study of the textile potential of Tunisian dromedary hairs [Ph.D. thesis], ENIM, Monastir University, Al Munastîr, Tunisia, 2010.
[28] D. M. Lewis, "Wool dyeing," in Society of Dyers and Colourists, D. M. Lewis, Ed., pp. 112-116, 1992.

[29] A. Bereck, "Bleaching of dark fibres in wool," in Proceedings of the 7th International Wool Textile Research Conference, vol. 4, pp. 152-161, Tokyo, Japan, 1985.

[30] K. Oh, M. Park, and T. Kang, "Effect of mordant bleaching on the optical and mechanical properties of black human hair," Journal of the Society of Dyers and Colourists, vol. 113, no. 9, pp. 243-249, 1997.

[31] L. J. Wolfram, K. Hall, and I. Hui, "The mechanism of hair bleaching," Journal of the Society of Cosmetic Chemists, vol. 21, pp. 875-900, 1970.

[32] J. F. Corbett, "The chemistry of hair-care products," Journal of the Society of Dyers and Colourists, vol. 92, pp. 285-303, 1976. 

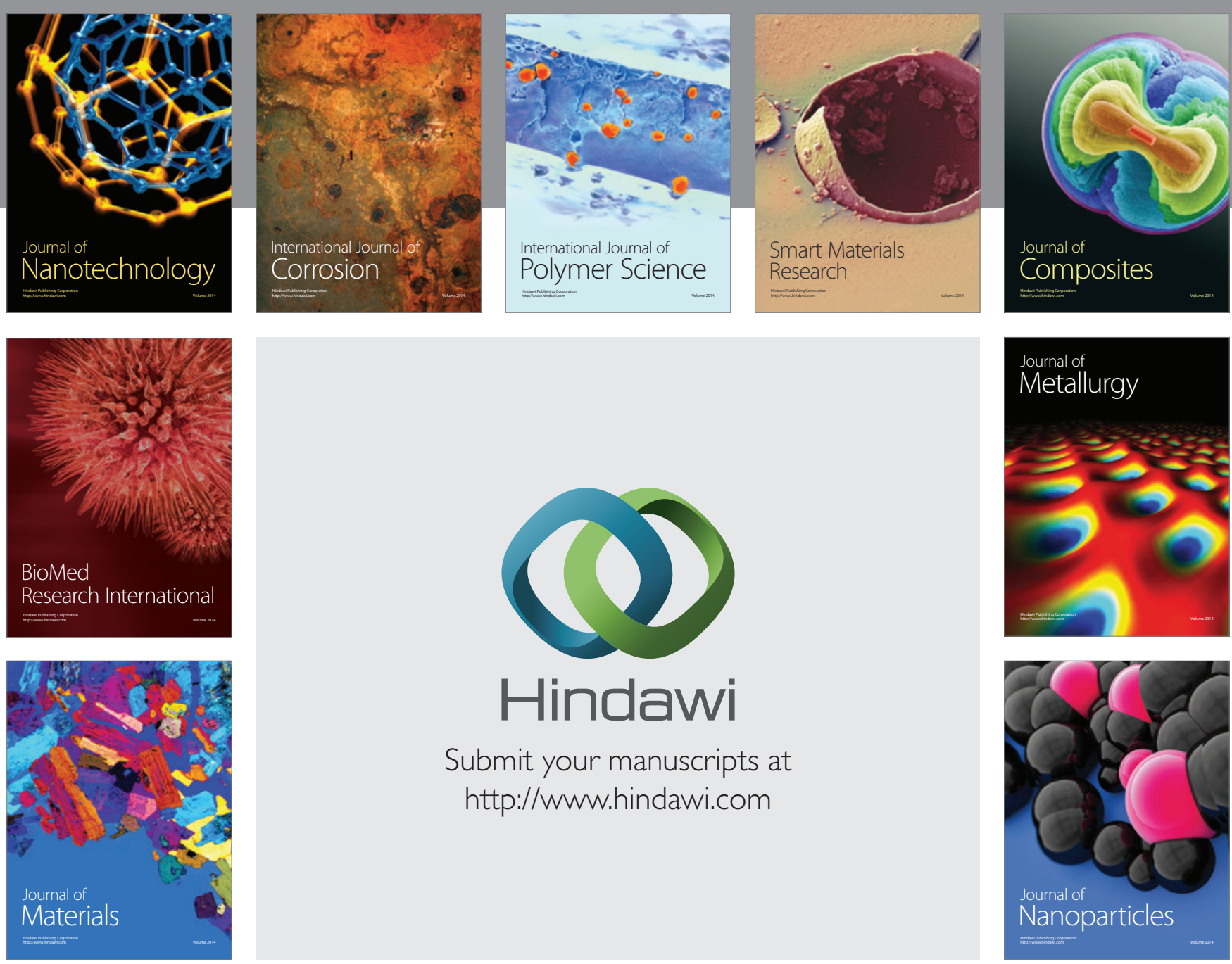

Submit your manuscripts at http://www.hindawi.com
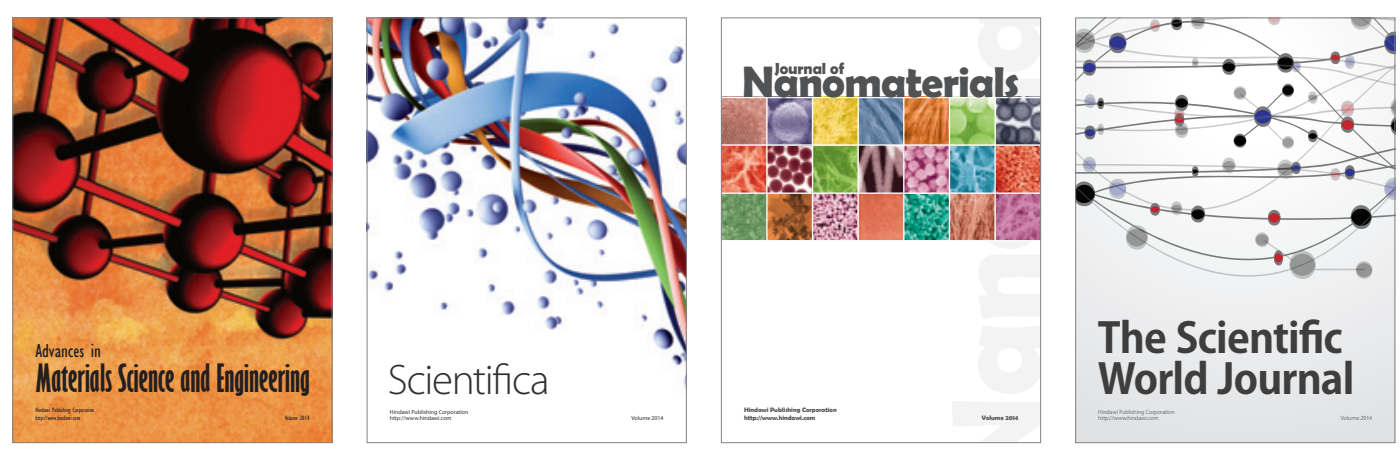

\section{The Scientific World Journal}
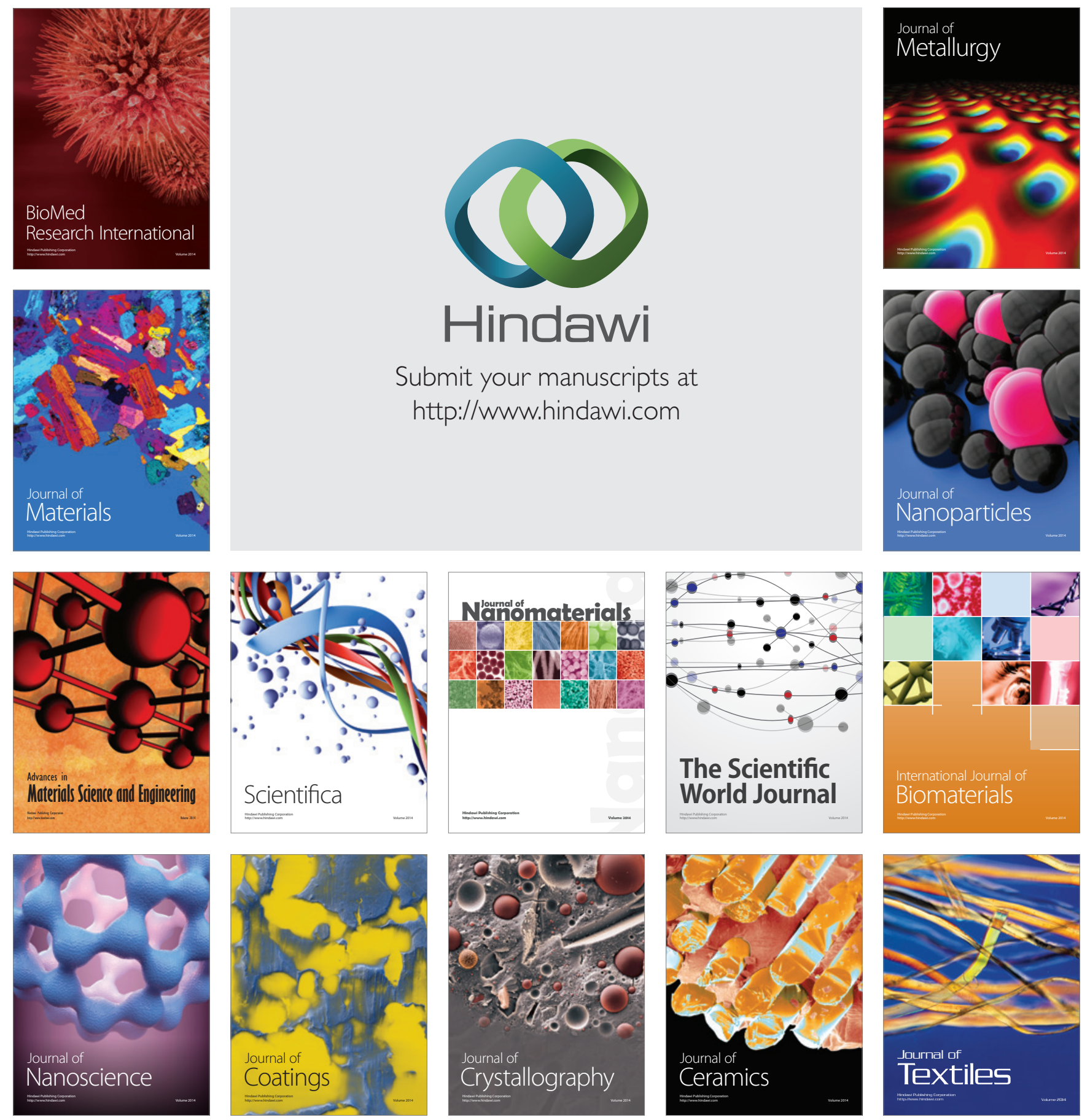